\title{
Author Correction: Understanding the plume dynamics of explosive super-eruptions
}

\author{
Antonio Costa (iD) ${ }^{1}$, Yujiro J. Suzuki ${ }^{2} \&$ Takehiro Koyaguchi ${ }^{2}$
}

Correction to: Nature Communications https://doi.org/10.1038/s41467-018-02901-0; published online 12 Feb 2018

We became aware of a mistake in the data displayed in the original version of Fig. 3. Specifically, the lines showing the relationship between column height and MFR for MFR larger than $10^{10} \mathrm{~kg} / \mathrm{s}$ were based on simulations in which the exit gas fraction was assumed to be an unrealistic value of 0.76 rather than the correct value of 0.33 . The correct version of Fig. 3 is:

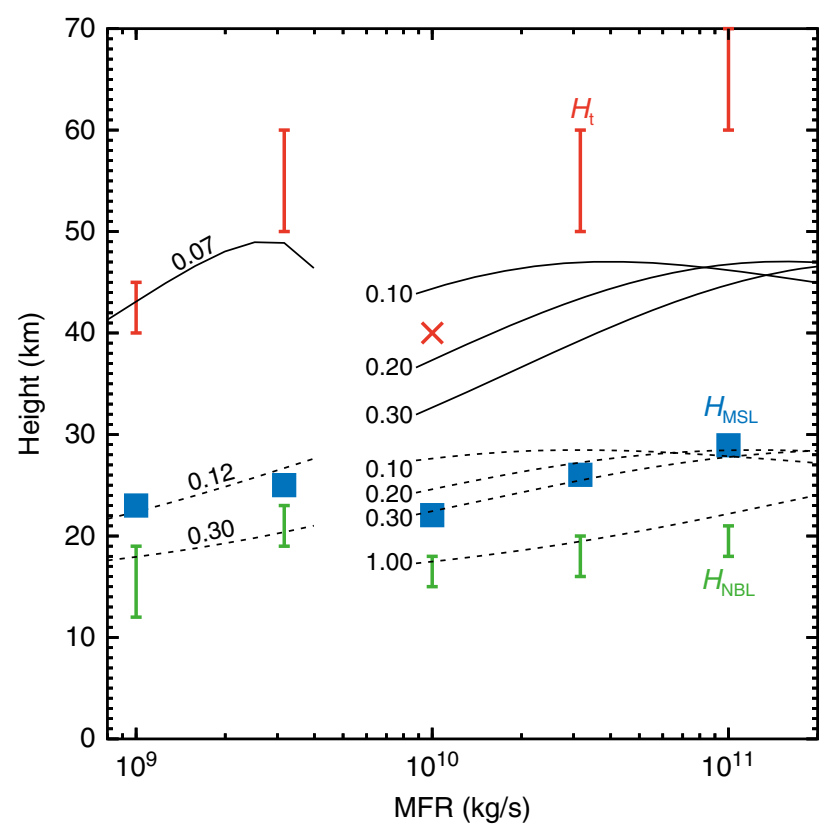

Fig. 3

\footnotetext{
${ }^{1}$ Istituto Nazionale di Geofisica e Vulcanologia, 40128 Bologna, Italy. ${ }^{2}$ Earthquake Research Institute, University of Tokyo, 1-1-1 Yayoi, Bunkyo-ku, Tokyo 1130032, Japan. Correspondence and requests for materials should be addressed to A.C. (email: antonio.costa@ingv.it)
} 
which replaces the previous incorrect version:

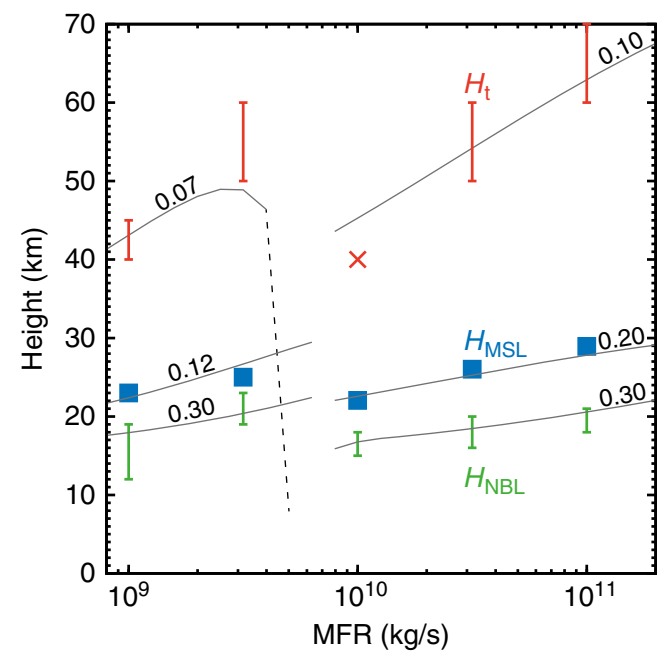

This has been corrected in both the PDF and the HTML versions of the Article. The text was written on the basis of the correct plots, and so this error does not affect the original discussion or conclusions of the Article. The authors apologize for the confusion caused by this mistake.

Published online: 22 August 2018

\begin{abstract}
(c) (1)
Open Access This article is licensed under a Creative Commons Attribution 4.0 International License, which permits use, sharing, adaptation, distribution and reproduction in any medium or format, as long as you give appropriate credit to the original author(s) and the source, provide a link to the Creative Commons license, and indicate if changes were made. The images or other third party material in this article are included in the article's Creative Commons license, unless indicated otherwise in a credit line to the material. If material is not included in the article's Creative Commons license and your intended use is not permitted by statutory regulation or exceeds the permitted use, you will need to obtain permission directly from the copyright holder. To view a copy of this license, visit http://creativecommons.org/licenses/by/4.0/.
\end{abstract}

(c) The Author(s) 2018 